\title{
Glomangioma of the trachea: A case report and literature review
}

\author{
YANG TAN $^{1}$, PENG YANG $^{2}$, XIAOYU DENG ${ }^{2}$ and YAN TANG $^{2}$ \\ ${ }^{1}$ Department of Pathology, Dujiangyan Maternal and Child Health Care Hospital, Chengdu, Sichuan 611830; \\ ${ }^{2}$ Department of Pathology, The Third People's Hospital of Chengdu, Chengdu, Sichuan 610031, P.R. China
}

Received March 28, 2014; Accepted December 12, 2014

DOI: $10.3892 / \mathrm{ol} .2015 .2871$

\begin{abstract}
A 44-year-old male presented with progressing cough, dyspnea and hemoptysis due to a tracheal tumor involving the posterior wall of the lower trachea, with severe airway obstruction and coagulopathy. Consequently the patient underwent segmental resection of the trachea with an end-to-end anastomosis. Twenty months after treatment there remained no evidence of endobronchial recurrence at bronchoscopy or imaging studies. The diagnosis was benign tracheal glomus tumor (GT) which is an exceedingly rare mass lesion in the trachea. There are three subtypes: GT proper, glomangioma and glomangiomyoma. The present study describes the clinical and pathological features of glomangioma through a case report and literature review. To the best of our knowledge, this is the fifth report of glomangioma subtype arising from the trachea.
\end{abstract}

\section{Introduction}

Glomus tumors (GTs) are neoplasms arising from the modified smooth muscle cells surrounding arteriovenous anastomosis $(1,2)$. GT is an uncommon soft tissue tumor with an incidence of $1.6 \%$, which is usually located in the dermis and subcutaneous tissue, with $\leq 65 \%$ occurring in the subungual area. Due to sparse or absent glomus bodies in the visceral organs, extracutaneous presentation of GT is rarely observed (3-8). Previously reported atypical sites of origin include the stomach, mediastinum, vagina, penis, lung, patella and trachea. Histologically, GTs have been divided into three subtypes: Classic glomus tumors, glomangiomas, and glomangiomyomas. Glomangiomas are an uncommon type, accounting for $<20 \%$ of GTs $(1,2,9-11)$. Until now, only 27 cases of GTs, and five reports of glomangioma subtype arising from the trachea, including the present case, have been reported (8-32). GTs are usually benign and recurrence rates

Correspondence to: Professor Yan Tang, Department of Pathology, The Third People's Hospital of Chengdu, 82 Qinlong Lane, Chengdu, Sichuan 610031, P.R. China

E-mail: luyibingli@163.com

Key words: glomus tumor, glomangioma, trachea, segmental resection are variable, ranging from 10 to $30 \%(1,2)$. The present study reported a primary GT of the trachea, which is a possible differential diagnostic alternative when a tracheal tumor is detected by radiographic or endoscopic examination. Written informed consent was obtained from the patient and the patient's family.

\section{Case report}

A 44-year-old male, exhibiting a defined tracheal tumor that was diagnosed by the local hospital (Bazhou People's Hospital, Bazhou, China) two months earlier, was admitted to our hospital (The Third People's Hospital of Chengdu, Chengdu, China) due to acute respiratory distress. The patient had suffered from cough, expectoration and dyspnea without any evident incentive for $>1$ year. Six days before admission, the symptoms were aggravated with hemoptysis. A chest X-ray scan was found to be normal. However, a computed tomographic (CT) scan revealed a demarcated homogenous intratracheal mass at the layer of the superior border of the manubrium (Fig. 1). Flexible bronchoscopy revealed a sessile tumor with a smooth surface arising from the posterior wall of the trachea, which occluded $\sim 90 \%$ of the trachea lumen, at $3 \mathrm{~cm}$ proximal to the carina. A biopsy was performed to elucidate the nature of the tumor. At $3 \mathrm{~h}$ after referral, the patient exhibited no response to voice and became signally dyspneic and cyanotic in the face and extremities, which indicated apnea induced by neoplastic obstruction.

To prevent mortality and restore the airway, endotracheal intubation was conducted initially using a rigid tracheoscope under surface anesthesia. Due to the unstable condition of the patient, comprehensive treatment was administered to prepare for the operation. A preoperative coagulation profile revealed prolonged activated partial thromboplastin time (APTT; $68.3 \mathrm{sec}$ ) and prothrombin time (PT; $19.1 \mathrm{sec})$, which indicated an increased risk for the surgery. With plasma transfusion, after five days the patient underwent segmental resection of the trachea with an end-to-end anastomosis and the bilateral pulmonary infection led to a poor general postoperative condition. Due to being bed-ridden postoperatively, 13 days following the surgery the patient exhibited femoral and deep vein thrombosis. Thrombolytic therapy was challenging, due to the persistent bleeding disorder. To prevent pulmonary embolus, vena cava filters were placed and clot-busting therapy was conducted simultaneously. The patient was discharged without the support of ventilation 26 days after presentation. 
Table I. Antibody panel used in this case study.

\begin{tabular}{llcc}
\hline Antibody/molecule & \multicolumn{1}{c}{ Clone } & Dilution & Expression \\
\hline SMA & 1A4 & $1: 70$ & $(+)$ \\
Vimentin & SP20 & $1: 70$ & $(+)$ \\
Desmin & D33 & $1: 70$ & $(-)$ \\
Pan-cytokeratin & AE1/AE3 & $1: 70$ & $(-)$ \\
Chromogranin & SP12 & $1: 70$ & $(-)$ \\
Synaptophysin & SP11 & $1: 70$ & $(-)$ \\
S-100 & 4C4.9 & $1: 70$ & $(-)$ \\
Calfetinin & Polyclone & $1: 60$ & $(-)$ \\
LCA & ZB11+PD7/26 & $1: 70$ & $(-)$ \\
Melanosome & HMB-45 & $1: 70$ & $(-)$ \\
CD99 & SP119 & $1: 70$ & $(-)$ \\
\hline
\end{tabular}

Antigen retrieval was PH9.0EDTA (microwave), and Zeta Corporation (Sierra Madre, CA, USA) provided the mouse anti-human monoclonal antibodies for the present study. (+), positive; (-), negative; CD99, cluster of differentiation 99; SMA, smooth muscle actin; LCA, leukocyte common antigen.

Three months after resection, the patient underwent follow-up with CT and endoscopy to exclude focal recurrence or suspicious metastasis. The lumen of the trachea remained clear for 20 months after the surgery.

The surgical specimen was $\sim 2 \mathrm{~cm}$ in length, with a luminal diameter of $2.5 \mathrm{~cm}$. The specimen exhibited a $3 \times 2.5 \times 1 \mathrm{~cm}$ red-brown mass sessile in the posterior wall of the trachea, which occupied the lumen as a polypoid mass (Fig. 2). Microscopically, the tumor was composed of epithelioid round to polygonal cells with defined cellular borders, weakly eosinophilic or clear cytoplasm and uniform round to ovoid nuclei. These formed solid sheets, small nests or organoidal structures surrounding dilated and tangled venous vessels, which were different from the thin-walled and capillary-like vascular channels normally observed in GT proper type. Cellular atypia and mitotic figures were absent (Fig. 3A). Gomori's staining demonstrated a delicate network of reticulum fibers lying between individual tumor cells (Fig. 3B). In addition, evidence of squamous metaplasia was observed in the intact overlying respiratory epithelium. Immunohistochemical staining revealed positivity for vimentin and smooth muscle actin antibodies (Fig. 3C). Pan-cytokeratin, desmin, chromogranin, synaptophysin, S-100, calfetinin, leukocyte common antigen, HMB-45 and cluster of differentiation 99 were negative (Table I). The tumor was diagnosed as a glomangioma.

\section{Discussion}

GTs are uncommon mesenchymal neoplasms. The etiology of these tumors remains a conundrum, and certain individuals attribute GTs to trauma, endocrine disorder or autosomal dominant inheritance $(1,2)$. Murray and Stout (2) indicated that GT often occurred in subungual hematoma and the fingertips of female patients, while in the extradigital tissues of male patients. This viewpoint coincides with previous studies on the tracheal GTs presented in Table II, in which the majority of cases involved male patients. GTs in the trachea are scarce.
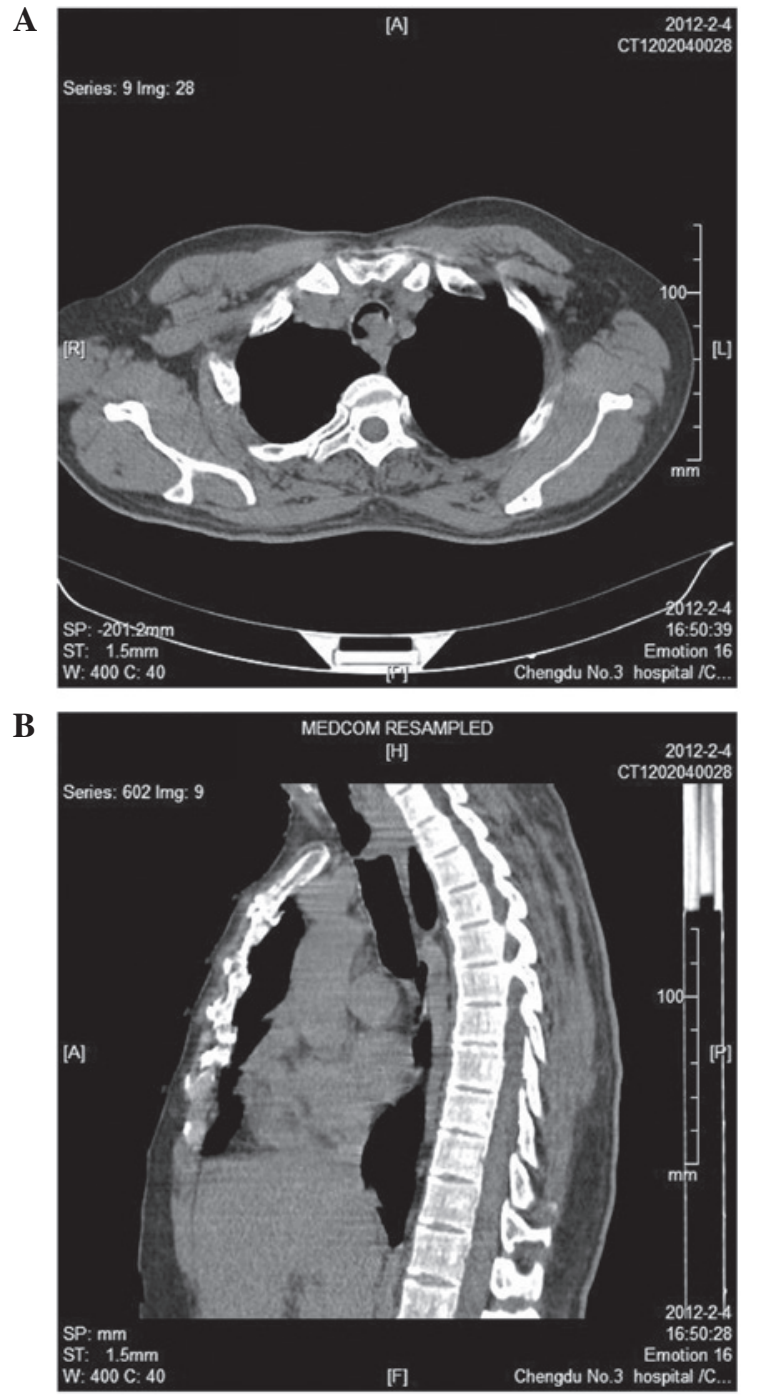

Figure 1. Computed tomograms of homogenous mass intratrachea at the layer of the superior border of the manubrium: (A) Transverse section and (B) median sagittal section of the chest.

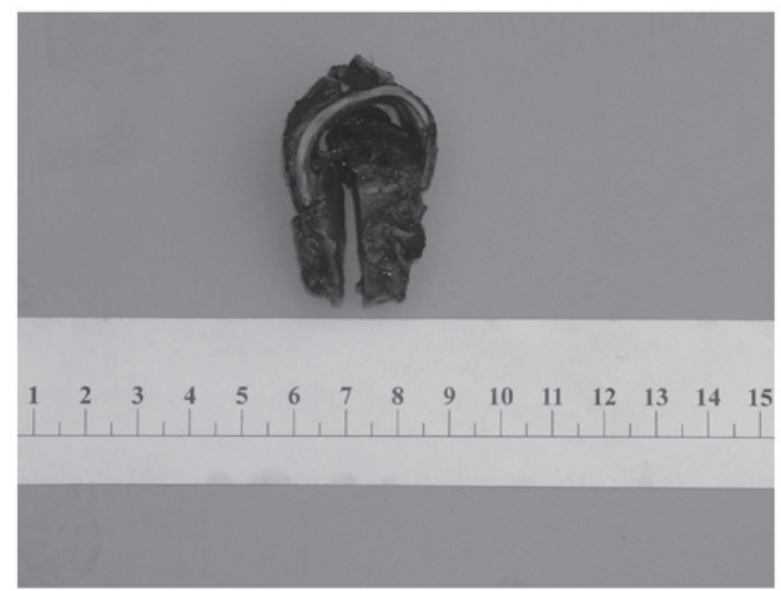

Figure 2. Resected tracheal specimen exhibits the mass arising from the posterior wall of the trachea.

The first GT case was reported in 1950 and, to the best of our knowledge, since then only 27 additional cases (including the present study) have been reported (Table II) (8-32). Based on 


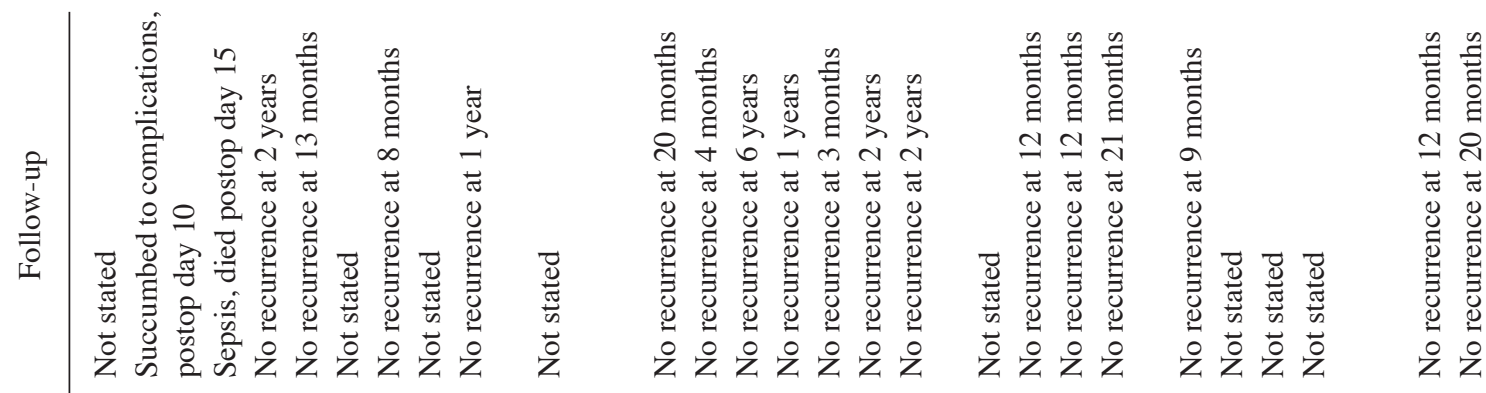

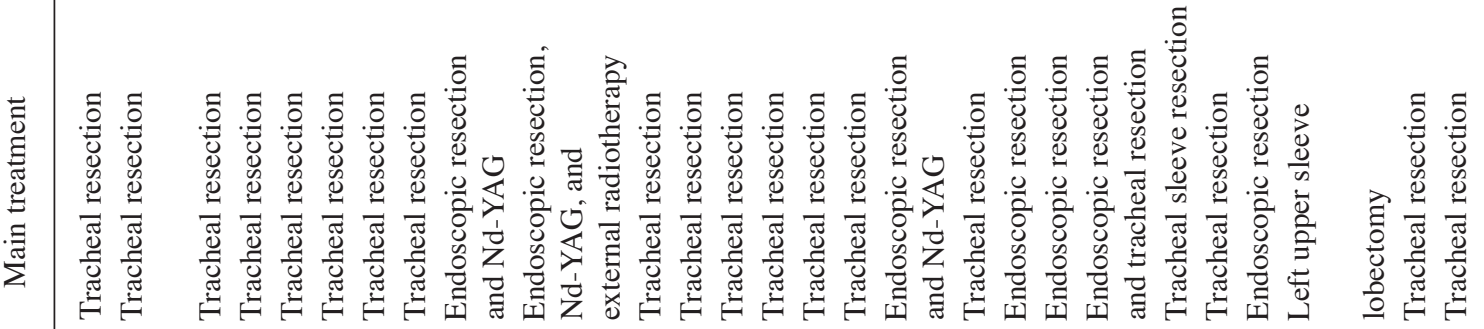

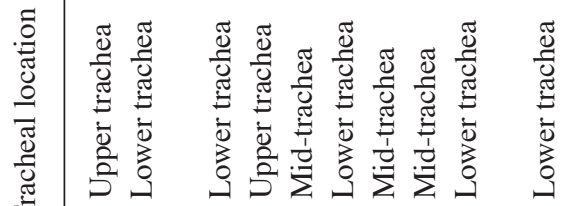

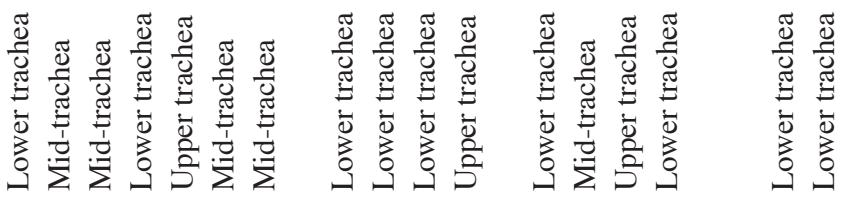

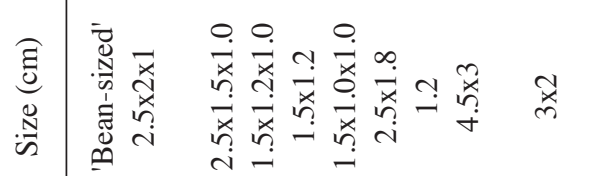

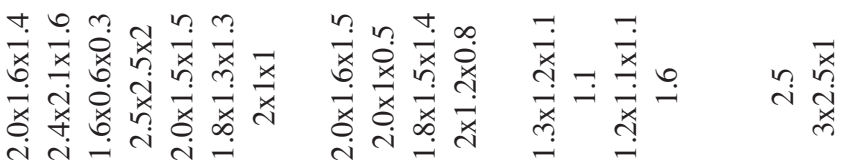

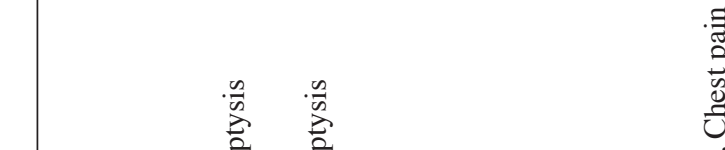

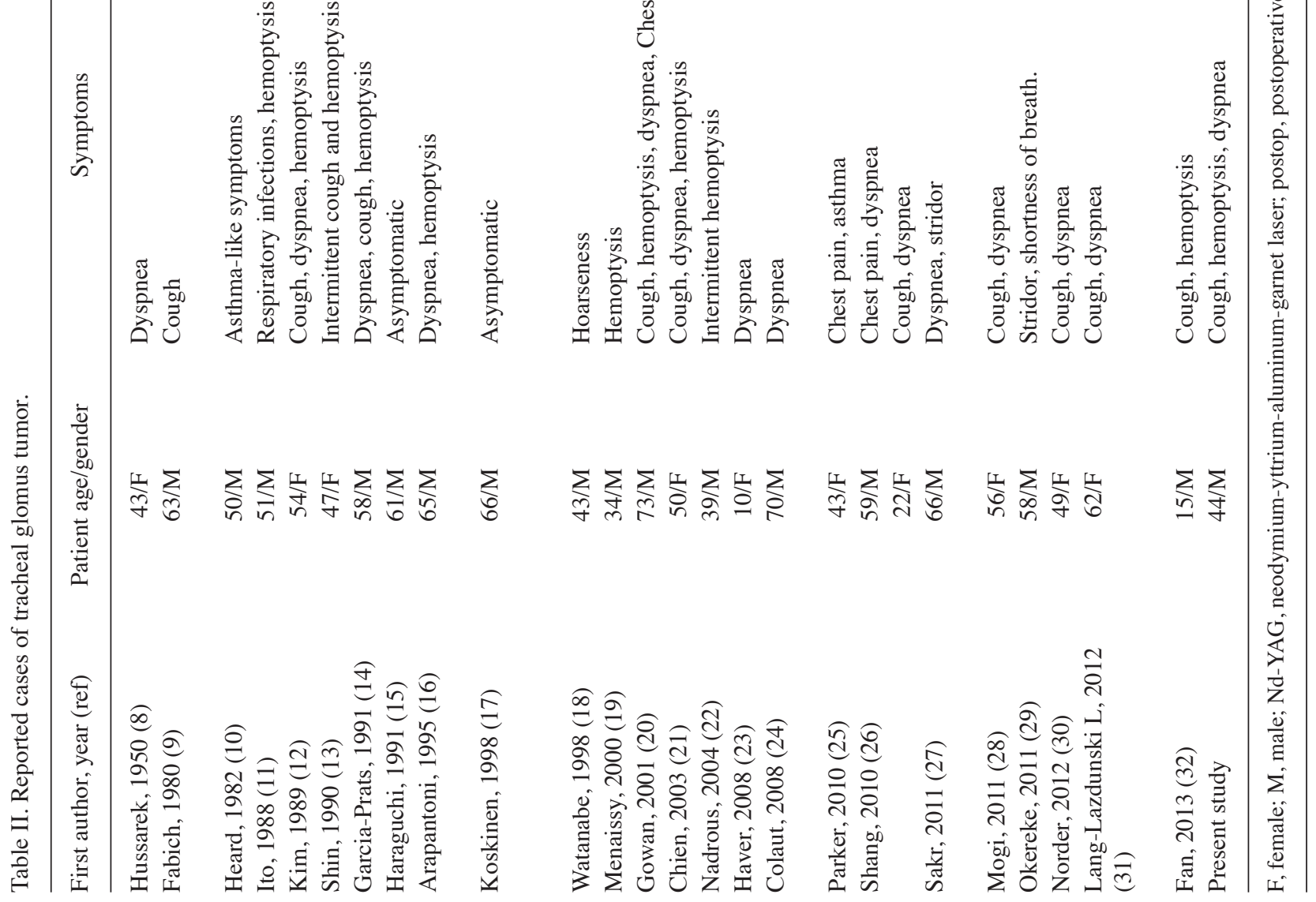


Table III. Summary characteristics of previously reported patients with glomus tumor of the trachea ${ }^{a}$.

\begin{tabular}{lc}
\hline Characteristic & Value \\
\hline Age, range (mean) & $10-73(50)$ \\
Male:Female & $1.6: 1$ \\
Symptoms, n (\%) & \\
Cough & $11(41)$ \\
Hemoptysis & $11(41)$ \\
Dyspnea & $15(56)$ \\
Chest pain & $3(11)$ \\
Asthma or stridor & $3(11)$ \\
None & $2(7)$ \\
Tumor size, range (mean) & $1.1-4.5(2.06)$ \\
Tumor location, $\mathrm{n}(\%)^{\mathrm{b}}$ & \\
Upper trachea & $5(18 \%)$ \\
Mid-trachea & $8(30 \%)$ \\
Lower trachea & $14(52 \%)$ \\
Treatment, $\mathrm{n}$ & \\
Tracheal resection & 19 \\
Endoscopic resection & 7 \\
Other & 1 \\
\hline
\end{tabular}

${ }^{\mathrm{a}}$ Data were obtained from references $8-32 .{ }^{\mathrm{b}} \mathrm{Certain}$ patients presented multiple symptoms: Symptoms (\%), number of patients with this symptom/total number of patients x 100; tumor location (\%), number of patients in this location/total number of patients x 100 .

the literature reviewed (Table III), the majority of cases have been identified on the posterior wall of the lower two-thirds of the trachea $(82 \%)$, where mucus glands and vessels are numerous. The cases included 16 males and 10 females (1.6:1), with a mean age of 50. The main symptoms included coughing, dyspnea and hemoptysis. Certain patients also suffered from chest pain, stridor and hoarseness. The mass diameter had a range of 1.2-4.5 cm. Almost all the tumors, including that of the present study, were benign and noninvasive.

To the best of our knowledge, no malignant GTs have been described in the trachea thus far. The histological morphology varies in subtypes according to the relative proportions of the glomus cells, vascular structures and smooth muscle tissue $(2,33)$. In addition to the classic three subtypes, including GT proper, glomangioma and glomangiomyoma, an oncocytic variant exists that was first described in 1990 (13). GT proper type accounts for $\sim 75 \%$ of all the GTs, which also applies to the tracheal mass, while glomangioma occupies $20 \%$ of all the cases (Table II). The oncocytic tumors are the least common, comprising $1 / 20$ of all the tracheal GTs reported in the literature (13). In the present study, the tumor was characterized by organoid nests and solid sheets of uniform round or polygonal cells around the venous vessels, but not thin-walled or capillary-like vascular channels. This is the fifth description of a glomangioma arising from the trachea. In the study by Shin et al, the round glomus cells represented the largest component of tumor cells surrounding the thin-walled vascular spaces, leading to the hypothesis that this may be a subtype of glomangioma (13). Based on the Pathology and Genetics of Tumors of Soft Tissue and Bone (World Health Organization

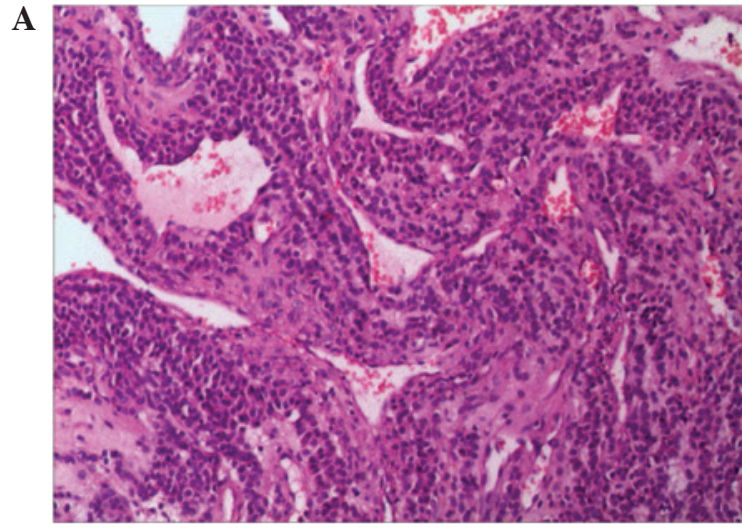

B

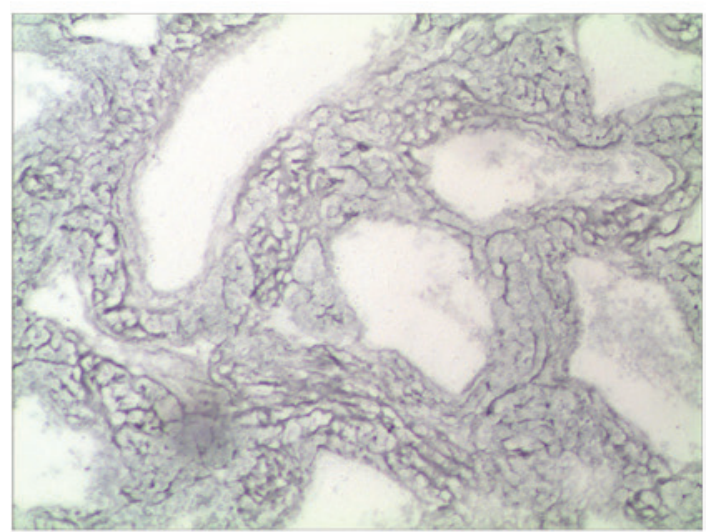

C

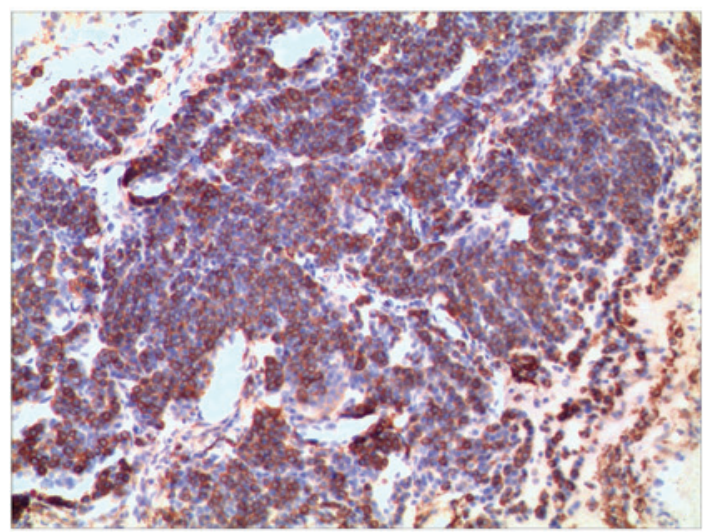

Figure 3. (A) Uniform polygonal cells with round to ovoid nuclei and slightly eosinophilic cytoplasm surrounded by dilated capillary-sized vessels (hematoxylin and eosin; magnification, x200). (B) Reticulin stain revealed a delicate network of reticulum fibers lying between individual tumor cells (magnification, $\mathrm{x} 200$ ). (C) On immunohistochemical evaluation, tumor cells were stained for smooth muscle actin (magnification, x200).

Classification of Tumors), the main histological characteristic of glomangioma is that the glomus cell clusters are arranged around dilated venous vessels (33). The immunohistochemical features have contributed to differential diagnosis with carcinoid and hemangiopericytoma $(28,32,33)$. GTs are positive for vimentin and smooth musle actin, but negative for neuroendocrine and epithelial markers, including S-100 protein, chromogranin, desmin, cytokeratins and factor VIII.

To avoid local recurrence, tracheal resection is widely used and exhibits favorable prognosis (Table II). Endoscopic intervention alone is also applied in a limited number of cases, which has rigorous indications if: The lesion is strictly confined without extension; histology confirms the tumor is 
benign; as a temporary measure for surgery preparation; or the patient is not fit or willing to undergo surgical resection. In addition, interventional bronchoscopy is a first-line treatment to immediately restore the airway patency in urgent situations $(14,16,17,25-27,30)$.

Furthermore, as an uncommon site, treating the complications and accompanying diseases during the perioperative period is crucial in order to increase survival rates. The main cause of mortality reported in the literature following surgery was not the primary tumor or the procedure but the complications $(9,10)$. The present patient exhibited a severe clinical condition and the symptoms were caused by tumor obstruction. Therefore, endotracheal intubation was performed to aid the recovery of the stabilization, ensuring that the patient fit for the procedure. Due to his severe coagulopathy, preoperative correction of coagulation disturbance was performed to prepare for the surgery. The filters of the vena cava and warfarin administration were arranged simultaneously following surgery to treat femoral and deep vein thrombosis caused by a long time period in bed. Active sputum excretion, prevention of infections and early mobilization is beneficial for recovery.

In conclusion, previous studies and the present report reveal that the incidence of GTs in the trachea is low and these tumors primarily occur in males, with unknown etiology and concealed onset. Patients with GTs usually resort to medical attention for symptoms of airway obstruction. CT imaging, magnetic resonance imaging and flexible bronchoscopy of GTs reveal a lumen-occupying lesion. Surgical management is generally the primary option and histopathological examination may determine the diagnosis. The long-term prognosis of the disease is promising.

\section{References}

1. Enzinger FM, Weiss SW and Chandrasekhar B: Soft tissue tumors. PRS Journal 76: 153-155, 1985.

2. Murray MR and Stout AP: The glomus tumor: Investigation of its distribution and behavior, and the identity of its 'epithelioid' cell. Am J Pathol 18: 183-203, 1942.

3. Kanwar YS and Manaligod JR: Glomus tumor of the stomach. An ultrastructural study. Arch Pathol 99: 392-397, 1975.

4. Brindley GV Jr: Glomus tumor of the mediastinum. J Thorac Surg 18: 417-420, 1949.

5. Banner EA and Winkelmann RK: Glomus tumor of the vagina; report of a case. Obstet Gynecol 9: 326-328, 1957.

6. Graner BC and Burt JC: Unusual location of glomus tumor: report of two cases. JAMA 112: 1806-1810, 1939.

7. Tang CK, Toker C, Foris NP and Trump BF: Glomangioma of the lung. Am J Surg Pathol 2: 103-109, 1978.

8. Hussarek M and Rieder W. Glomus tumor of the trachea. Krebsarzt 5: 208-212, 1950 (In Undetermined Language).

9. Fabich DR and Hafez GR: Glomangioma of the trachea. Cancer 45: 2337-2341, 1980.
10. Heard B E, Dewar A, Firmin R K, et al. One very rare and one new tracheal tumour found by electron microscopy: glomus tumour and acinic cell tumour resembling carcinoid tumours by light microscopy. Thorax 37: 97-103, 1982.

11. Ito H, Motohiro K, Nomura S, et al. Glomus tumor of the trachea: immunohistochemical and electron microscopic studies. Pathology-Research and Practice 183: 778-782, 1988.

12. Kim Y I, Kim J H, Suh J S, et al. Glomus tumor of the trachea. Report of a case with ultrastructural observation. Cancer, 64: 881-886, 1989.

13. Shin DH, Park SS, Lee JH, et al: Oncocytic glomus tumor of the trachea. Chest 98: 1021-1023, 1990.

14. García-Prats MD, Sotelo-Rodríguez MT, Ballestín C, et al: Glomus tumour of the trachea: report of a case with microscopic, ultrastructural and immunohistochemical examination and review of the literature. Histopathology 19: 459-464, 1991.

15. Haraguchi S, Yamamoto $M$ and Nishimura $\mathrm{H}$ : A glomus tumor of the trachea - a case report. Nihon Kyōbu Geka Gakkai 39: 214-218, 1991.

16. Arapantoni-Dadioti P, Panayiotides J, Fatsis M and Antypas G: Tracheal glomus tumour. Respiration 62: 160-162, 1995.

17. Koskinen SK, Niemi PT, Ekfors TO, et al: Glomus tumor of the trachea. Eur J Radiol 8: 364-366, 1998.

18. Watanabe M, Takagi K, Ono K, et al: Successful resection of a glomus tumor arising from the lower trachea: report of a case. Surg Today 28: 332-334, 1998.

19. Menaissy YM, Gal AA and Mansour KA: Glomus tumor of the trachea. Ann Thorac Surg 70: 295-297, 2000.

20. Gowan RT, Shamji FM, Perkins DG and Mazaik DE: Glomus tumor of the trachea. Ann Thorac Surg 72: 598-600, 2001.

21. Chien ST, Lee TM, Hsu JY, et al: Glomus tumor of the trachea. J Chin Med Assoc 66: 551-554, 2003.

22. Nadrous HF, Allen MS, Bartholmai BJ, et al: Glomus tumor of the trachea: value of multidetector computed tomographic virtual bronchoscopy. Mayo Clin Proc 79: 237-240, 2004.

23. Haver KE, Hartnick CJ, Ryan DP, et al: Case records of the Massachusetts General Hospital. Case 10-2008. A 10-year-old girl with dyspnea on exertion. N Engl J Med 358: 1382-1390, 2008.

24. Colaut F, Toniolo L, Scapinello A and Pozzobon M: Tracheal glomus tumor successfully resected with rigid bronchoscopy: a case report. J Thorac Oncol 3: 1065-1067, 2008.

25. Parker KL, Zervos MD, Donington JS, et al: Tracheal glomangioma in a patient with asthma and chest pain. J Clin Oncol 28: e9-e10, 2010.

26. Shang Y, Huang Y, Huang HD, et al: Removal of glomus tumor in the lower tracheal segment with a flexible bronchoscope: report of two cases. Intern Med 49: 865-869, 2010.

27. Sakr L, Palaniappan R, Payan MJ, et al: Tracheal glomus tumor: a multidisciplinary approach to management. Respir Care 56: 342-346, 2011

28. Mogi A, Kosaka T, Yamaki E, et al: Successful resection of a glomus tumor of the trachea. Gen Thorac Cardiovasc Surg 59: 815-818, 2011.

29. Okereke IC, Sheski FD and Cummings OW: Glomus tumor of the trachea. J Thorac Oncol 6: 1290-1291, 2011.

30. Norder E, Kynyk J, Schmitt AC, et al: Glomus tumor of the trachea. J Bronchology Interv Pulmonol 19: 220-223, 2012.

31. Lang-Lazdunski L, Bille A, Cane P and Congleton J: Glomus tumour: a rare differential diagnosis of bronchial obstruction in a smoker. Gen Thorac Cardiovasc Surg 60: 774-776, 2012.

32. Fan M, Liu C, Mei J, et al: A rare large tracheal glomus tumor with postoperative haematemesis. J Thorac Dis 5: E185-E188, 2013.

33. Kleihues P and Sobin LH. World Health Organization classification of tumors. Cancer 88: 2887, 2000. 